\title{
Modulation of Aphid Vector Activity by Potato virus Y on In Vitro Potato Plants
}

S. Boquel, Université de Picardie Jules Verne, Laboratoire de Biologie des Entomophages, 80039 Amiens Cedex, France, and GIE, Station de Recherche et de Création Variétale du Comité Nord, 76110 Bretteville-du-Grand-Caux, France; and C. Delayen, A. Couty, P. Giordanengo, and A. Ameline, Université de Picardie Jules Verne, Laboratoire de Biologie des Entomophages, 80039 Amiens Cedex, France

\begin{abstract}
Boquel, S., Delayen, C., Couty, A., Giordanengo, P., and Ameline, A. 2012. Modulation of aphid vector activity by Potato virus $Y$ on in vitro potato plants. Plant Dis. 96:82-86.

The effects of the infection of potato (Solanum tuberosum) plants by the nonpersistent Potato virus Y (PVY) were studied on the host plant colonization behavior of different colonizing (Myzus persicae) and noncolonizing (Aphis fabae, Brevicoryne brassicae, and Sitobion avenae) aphid species. The underlying questions of this study were to know how aphids respond when faced with PVY-infected plants and whether plant infection can modify the aphid behavior involved in PVY spread. Short-range orientation behavior was observed using a dual-choice set-up and aphid feeding behavior was monitored using the electrical penetration graph technique. None of the aphid species discriminated between healthy and PVY-infected plants. Nevertheless,

most individuals of $M$. persicae landed on and probed only in one plant whereas noncolonizing aphid species exhibited interplant movements. Study of the aphid feeding behavior showed that PVY infection essentially modified phloem and xylem ingestion. M. persicae and S. avenae exhibited an increased duration of phloem phases on PVY-infected plants whereas A. fabae showed a decreased duration of phloem phases that benefited from an increased duration of xylem ingestion phases. None of these parameters were changed in B. brassicae. These data present evidence that aphids can respond to plants infected by nonpersistent viruses. Such behavioral modifications are discussed within the context of PVY spread in potato crops.
\end{abstract}

Plant colonization by alate aphids is achieved through a sequence of behaviors, which involves perception of several stimuli $(36,44)$. Host habitat location and host location are mainly governed by visual $(10,26)$ and chemical cues $(36,39)$. After landing on a plant, the aphid assesses the physical and chemical properties of the leaf and odor blends. Then, gustative cues are perceived through brief intracellular stylet insertions into epidermal and mesophyll cells to evaluate host plant quality (42). Finally, after phloem assessment through gustative cues, host acceptance occurs, which leads to sustained phloem sap ingestion $(6,29,36,44)$. Throughout this sequence, the plant may either be recognized as a host or induce aphid flight if the plant is rejected (42).

Virus infection may affect the behavior and the biology of its aphid vectors. Some species preferentially colonize virus-infected plants while others avoid them (13). The yellowing of virusinfected leaves was shown to preferentially attract aphids, acting as visual cues $(12,20,21)$. Virus infection can also modify the headspace volatiles emitted by the plants. Potato (Solanum tuberosum L.) plants infected by the persistent Potato leafroll virus (PLRV) (Luteoviridae: Polerovirus) emitted a higher quantity of volatile organic compounds (VOCs) than healthy ones, thus increasing Myzus persicae settling on infected plants $(8,11,49)$. Such preference in response to variations in the emitted VOCs was also reported in wheat infected by the persistent Barley yellow dwarf luteovirus (BYDV) (Luteoviridae: Luteovirus) with regards to Rhopalosiphum padi $(24,32)$. Other results reported that Potato virus $Y$ (PVY) (Potyviridae: Potyvirus)-infected potato did not disturb $M$. persicae settling behavior (8). Intracellular probes into superficial tissues and phloem sap ingestion can also be enhanced in M. persicae on PLRV-infected potato plants (1) and in Sitobion avenae on BYDV-infected wheat (15). Finally, both PLRV and PVY infections were reported to improve $M$. persicae fitness $(7,49)$. Simi-

Corresponding author: S. Boquel, E-mail: sebastien.boquel@u-picardie.fr

Accepted for publication 13 August 2011.

http://dx.doi.org/10.1094/PDIS-06-11-0499

(C) 2012 The American Phytopathological Society larly, $R$. padi fitness was also improved on BYDV-infected wheat (23). However, Bean yellow mosaic virus (BYMV) (Potyviridae: Potyvirus)-infected beans were reported to negatively affect settling and the performance of Acyrthosiphon pisum (45).

When transmitted in a nonpersistent manner, PVY is one of the most economically important viruses affecting potato crops all around the world (46). The efficiency of its transmission relies on the early steps of host plant colonization and, more particularly, on the very brief ( 5 to $10 \mathrm{~s}$ ) intracellular punctures (22) in epidermal and mesophyll cells that provide the aphid information for plant quality assessment (40). These intracellular punctures consist of the injection of saliva within the cytosol and, subsequently, the ingestion of a saliva/cytoplasm mixture, which occurs a few seconds later. They are responsible for the acquisition (during cell sampling) and the inoculation (during salivation) of stylet-borne viruses $(13,30,41)$. Thus, any aphid that alights on and probes the plant may be a potential vector of PVY. The green peach aphid, $M$. persicae, is reported as the most efficient vector of $\mathrm{PVY}$ in potato fields. Even when very low densities of potato-colonizing aphids are trapped, potato crops still show high virus infection rates (3). In addition, high numbers of noncolonizing aphids are also trapped in the fields, some of which are reported as PVY vectors $(9,18,19,46,54,55)$. They are mostly represented by the cereal aphid, $S$. avenae, the pea aphid, A. pisum, the black bean aphid, Aphis fabae, and the cabbage aphid, Brevicoryne brassicae. Thus, it has been assumed that, in the absence of potato-colonizing aphid species, PVY spread is caused by these noncolonizing aphid species.

Because the spread of nonpersistent PVY mainly relies on the behavior of alate aphids, one could hypothesize that evolutionary constraints led such a pathogen to fine-tune plant physiology so as to improve the vectoring efficiency of these aphids. The previous works cited above attempted to deal with such a hypothesis by comparing the impact of different viruses on one aphid species. They brought divergent results, highlighting the complexity and specificity of the virus-plant relationship. In the present study, we investigated the effects of PVY infection on potato plants on the short-range orientation and feeding behavior of the alate morphs of different colonizing and noncolonizing potato aphids. We hypothesized that plants infected by a nonpersistent virus, as reported for plants infected by persistent viruses, could modulate the early steps 
of aphid host plant colonization behavior and, consequently, the aphid vector activity.

\section{Materials and Methods}

Insects. All the colonies of each species, which were M. persicae, A. fabae, S. avenae, and B. brassice, were initiated from a single apterous parthenogenetic female. Each colony was separately reared in an enclosed ventilated Plexiglas cage (360 by 240 by $110 \mathrm{~mm}$ ) in a growth chamber at $20 \pm 1{ }^{\circ} \mathrm{C}, 60 \pm 5 \%$ relative humidity (RH), and a photoperiod with $16 \mathrm{~h}$ of light and $8 \mathrm{~h}$ of darkness to induce parthenogenesis. In 1999, M. persicae was collected in a potato field near Loos-en-Gohelle (France). In 2008, A. fabae was collected in an eggplant greenhouse (Amiens, France) whereas $S$. avenae and $B$. brassicae were kindly provided by $\mathrm{D}$. Tagu (UMR-INRA-BIO3P, Le Rheu, France) and M. Uzest (UMRBGPI, Montpellier, France), respectively.

$M$. persicae was reared on potato (Solanum tuberosum 'Désirée'), S. avenae on wheat (Triticum aestivum 'Mendel'), A. fabae on broad bean (Vicia faba 'Maya'), and B. brassicae on broccoli (Brassica oleracea 'Marathon'). Only alate aphids synchronized in their flight phase (4) were used for experiments.

In vitro plantlets and PVY ${ }^{\text {NTN }}$ isolate. The PVY-infected and healthy in vitro potato lines were created from a single potato tuber germ initially infected by the tuber necrotic strain of PVY ${ }^{\mathrm{NTN}}$ collected in a potato field in the north of France (Cambrai, France), and from a single noninfected tuber germ, respectively. In vitro healthy (H-P) and PVY-infected (PVY-P) plantlets (Solanum tuberosum L. 'Bintje') were then micropropagated by subculturing internode explants on a basal medium according to Murashige and Skoog (MS) (33) supplemented with sucrose and agar. Each plantlet was grown axenically for 15 days at $20 \pm 1{ }^{\circ} \mathrm{C}, 60 \pm 5 \% \mathrm{RH}$, and a photoperiod with $16 \mathrm{~h}$ of light and $8 \mathrm{~h}$ of darkness in small glass vials $(5 \mathrm{ml})$ placed in a sterile culture glass tube $(25$ by $150 \mathrm{~mm})$. The small glass vials containing plantlets could then easily be removed for the experiments. The infection status of plantlets was assessed by immunocapture reverse-transcription polymerase chain reaction following the protocol described by Glais et al. (17). The virus check was done a posteriori for each plant used. Immediately after every experiment (electrical penetration graph [EPG] or host choice test), each plant was crushed and assessed for PVY detection. If a plant was not infected by PVY as expected, relative experimental data were not included in the analysis.

Early steps of the colonization of the plantlets. The dualchoice set-up consisted of a ventilated Plexiglas chamber (180 by 120 by $75 \mathrm{~mm}$ ) wherein one H-P and one PVY-P in separate glass vials were set in small receptacles containing water to prevent aphids from colonizing the plantlets without engaging in flight (Fig. 1). Aphids were individually placed with a small paintbrush on the chamber floor between the two plantlets. At the end of the 24-h experiment, the aphids were removed from the chamber and their final choice (i.e., H-P, PVY-P, or inner wall of the chamber) was recorded. To check for the presence of salivary sheaths resulting from aphid stylet insertion in plant tissues, collected plantlets were stained with trypan blue adapted (i.e., plantlets were boiled 5 min and discolored $24 \mathrm{~h}$ ) from Koch and Slusarenko (27). The presence of salivary sheaths allowed for the determination of which plantlets were probed. For each aphid species, 30 replicates were done.

Feeding behavior on plantlets. The DC-EPG technique (51) was used to investigate the feeding behavior of each aphid species on H-P and PVY-P. A thin gold wire (diameter of $20 \mu \mathrm{m}, 2 \mathrm{~cm}$ long) was stuck with conductive water-based silver glue (EPG Systems, Wageningen, The Netherlands) on the aphid's dorsum and a copper electrode was inserted into the agar-based MS solution to complete the electrical circuit. Each aphid was then connected to a Giga-4 DC amplifier and carefully placed on a plantlet. Recordings were performed during daytime for $8 \mathrm{~h}$ in a Faraday cage in a growth room maintained at $20 \pm 2{ }^{\circ} \mathrm{C}$. At least 19 aphids were monitored for each treatment (H-P or PVY-P) and species.

Data acquisition and EPG waveform analyses were done with PROBE 3.5 software (EPG Systems). Fourteen parameters were selected to describe the feeding behavior and were calculated using the EPG-Calc 4.9 software (16). These parameters were based on five different EPG waveforms described by Tjallingii and HogenEsch (52): C, corresponding to stylet pathways in plant tissues except phloem and xylem; E1, salivation in phloem elements; E2, passive phloem sap ingestion; $G$, active xylem sap ingestion; $F$, derailed stylet mechanics; and pd, intracellular stylet punctures. The pd phase was divided into three subphases linked with nonpersistent virus transmission (43): II-1, intracellular salivation (virus inoculation); II2 , transition; and II-3, intracellular ingestion of saliva/cytosol mixture (virus acquisition). Parameters related to general probing $(\mathrm{C}$, E1, E2, F, and G; Table 1) were analyzed for the whole 8-h recording. Parameters related to intracellular probing (pd) (Table 1) were analyzed only during the first hour after the first probe.

Data analysis. Statistical analyses were performed using Statistica 8.0 software (StatSoft, Tulsa, OK). A Kruskal-Wallis one-way analysis of variance $(\mathrm{H})$ was performed to assess the effect of the aphid species on the distribution of salivary sheaths (i) in at least one plantlet and (ii) in both plantlets. When the Kruskal-Wallis test was significant, a Mann-Whitney $U$ test allowed for the determination of significant differences between species. For each aphid species, a $\chi^{2}$ test was done to compare the aphid distribution between H-P and PVY-P either throughout the experiment (deduced from the observation of aphid salivary sheaths) or at the end of the experiment (final choice). Because EPG data were not normally distributed, a pairwise comparison was done between the two treatments (H-P versus PVY-P) for each species with a Mann-Whitney $U$ test. A difference was considered significant when $P<0.05$.

\section{Results}

Early steps of the colonization of the plantlets. Distribution of aphids at the end of the 24-h dual-choice bioassay showed that three aphid species exhibited no preference in their final choice between H-P or PVY-P $\left(M\right.$. persicae: $\chi^{2}=0.03, \mathrm{df}=1, P<0.85 ; S$. avenae: $\chi^{2}=0.18 ; \mathrm{df}=1, P=0.67 ;$ A. fabae: $\chi^{2}=0.0$, df $=1, P=$ 1) (Fig. 2A). B. brassicae indicated no final choice because it was always found on the inner wall of the chamber. Aphid salivary sheaths, resulting from stylets insertion in plant tissues, were equally distributed on H-P and PVY-P (Fig. 2B). Interestingly, although $B$. brassicae was never recorded on plantlets at the end of the experiment, more than $60 \%$ performed probes either on $\mathrm{H}-\mathrm{P}$ or PVY-P (Fig. 3).

The percentage of salivary sheaths observed in at least one plantlet highly varied according to the aphid species tested $(\mathrm{H}=20.03$, $P<0.01$; Fig. 3). All M. persicae (100\%) probed in at least one

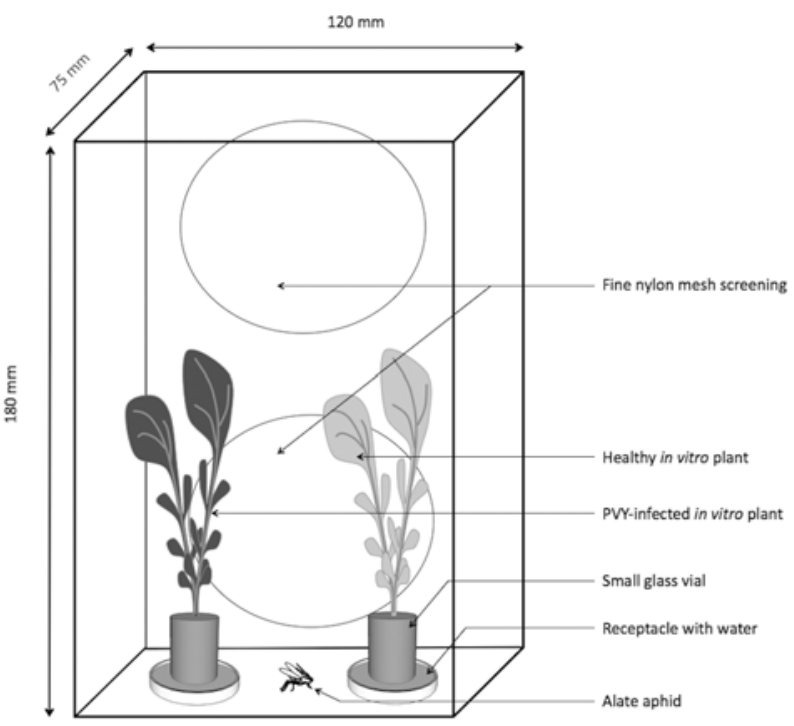

Fig. 1. Experimental device used for the 24-h dual-choice experiment. 
plantlet. This percentage was similar in $S$. avenae $(97 \%$; $\mathrm{U}=435$, $P=0.317)$. The percentage of salivary sheaths from $A$. fabae $(77 \%)$ and $B$. brassicae $(63 \%)$ in at least one plantlet was significantly lower than that from $S$. avenae $(\mathrm{U}=360, P<0.05$ and $\mathrm{U}=$ $300, P<0.01$, respectively) and $M$. persicae $(\mathrm{U}=345, P<0.01$ and $\mathrm{U}=285, P<0.01$, respectively).

There was also a significant difference between species in the distribution of salivary sheaths in both plantlets $(\mathrm{H}=12.16, P<$ 0.01 ; Fig. 3). Only $3.3 \%$ of $M$. persicae individuals probed in both plantlets whereas this proportion was significantly higher in $A$. fabae $(33 \%, \mathrm{U}=315, P<0.01), S$. avenae $(40 \%, \mathrm{U}=285, P<$ $0.01)$, and $B$. brassicae $(23 \%, \mathrm{U}=360, P<0.05)$.

Feeding behavior on plantlets. Among the 13 EPG parameters which allowed comparing aphid-feeding behavior on $\mathrm{H}-\mathrm{P}$ and PVY-P, 2 to 6 parameters were significantly modified depending on the species (Table 1).

In $M$. persicae general probing behavior, only parameters related to the activity within phloem vessels were modified. An increased number and total duration of phloem phases were observed on PVY-P $(\mathrm{U}=106, P<0.01$ and $\mathrm{U}=130, P<0.05$, respectively). Mean duration of potential drop and subphases II-2 and II-3 were also increased on PVY-P $(\mathrm{U}=96, P<0.01 ; \mathrm{U}=123, P<0.05$; and $\mathrm{U}=116, P<0.05$, respectively).

Similar modifications were observed in $S$. avenae general probing behavior. They exhibited an enhanced number and total duration of phloem phases on PVY-P $(\mathrm{U}=130, P<0.01$ and $\mathrm{U}=130$, $P<0.01$, respectively). Concerning intracellular probing behavior for this latter species, a higher number of potential drops was observed on PVY-P $(\mathrm{U}=117, P<0.05)$ but their mean duration was reduced ( $\mathrm{U}=84, P<0.01)$, as well as that of subphases II-1 and II3 (U $=63, P<0.01$ and $\mathrm{U}=108, P<0.05$, respectively).

A. fabae exhibited a reduced total duration of phloem phases on PVY-P $(\mathrm{U}=129, P<0.05)$ and spent more time ingesting xylem $(\mathrm{U}=115, P<0.05)$. None of the parameters of the intracellular probing behavior significantly differed between H-P and PVY-P.

Finally, in B. brassicae, the total duration of pathway phases and the mean duration of potential drops subphase II-1 were significantly shorter on PVY-P $(\mathrm{U}=106, P<0.05$ and $\mathrm{U}=67.5, P<$ 0.01 , respectively).

\section{Discussion}

Behavioral differences between colonizing and noncolonizing aphids were observed at different steps of the host plant coloniza-

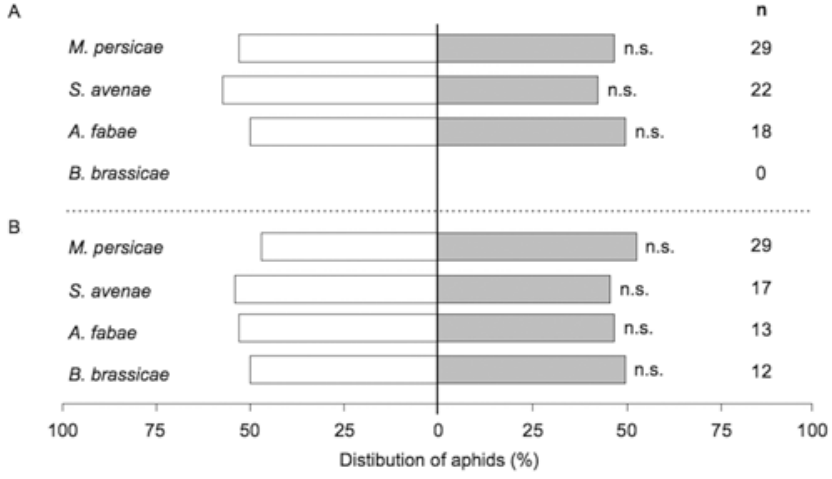

$\square$ Healthy plant $\square$ PVY-infected plant

Fig. 2. Distribution of the four aphid species on healthy (white bars) or Potato virus $Y$ (PVY)-infected (gray bars) Solanum tuberosum plantlets, resulting from $\mathbf{A}$, the number of individuals at the end of the 24-h dual-choice bioassay and $\mathbf{B}$, the presence of salivary sheaths; n.s. $=$ no significant difference at $P<0.05$ ( $\chi^{2}$ test); $n$ = number of responding aphids.

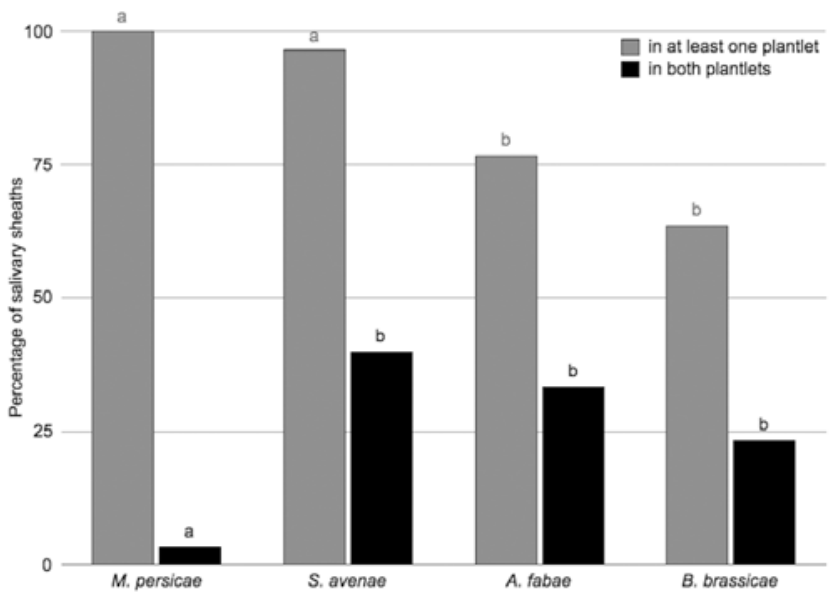

Fig. 3. Percentage of aphids probing in at least one plant (gray bars) and probing in both plants (black bars) throughout the 24-h experiment. For each of the four aphid species, 30 individuals were tested. Different letters indicate significant differences between species $(P<0.05$; Mann-Whitney $U$ test).

Table 1. Electrical penetration graph (EPG) parameters (mean \pm standard error) obtained during an 8-h recording session for four different aphid species on healthy (HP) and Potato virus Y (PVY)-infected in vitro Solanum tuberosum ('Bintje') plants

\begin{tabular}{|c|c|c|c|c|c|c|c|c|c|c|c|c|}
\hline \multirow[b]{2}{*}{ 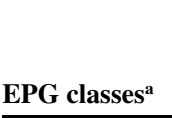 } & \multicolumn{3}{|c|}{ Myzus persicae } & \multicolumn{3}{|c|}{ Sitobion avenae } & \multicolumn{3}{|c|}{ Aphis fabae } & \multicolumn{3}{|c|}{ Brevicoryne brassicae } \\
\hline & $\begin{array}{c}\text { HP } \\
(n=20)\end{array}$ & $\begin{array}{c}\text { PVY } \\
(n=20)\end{array}$ & $\begin{array}{c}\mathbf{U} \\
(\mathbf{p})\end{array}$ & $\begin{array}{c}\text { HP } \\
(n=20)\end{array}$ & $\begin{array}{c}\text { PVY } \\
(n=20)\end{array}$ & $\begin{array}{c}\mathbf{U} \\
(\mathbf{p})\end{array}$ & $\begin{array}{c}\text { HP } \\
(n=20)\end{array}$ & $\begin{array}{c}\text { PVY } \\
(n=19)\end{array}$ & $\begin{array}{c}\mathbf{U} \\
(\mathbf{p})\end{array}$ & $\begin{array}{c}\text { HP } \\
(n=20)\end{array}$ & $\begin{array}{c}\text { PVY } \\
(n=20)\end{array}$ & $\begin{array}{c}\mathbf{U} \\
(\mathbf{p})\end{array}$ \\
\hline \multicolumn{13}{|l|}{ General $^{\mathrm{b}}$} \\
\hline 1. First probe ${ }^{\mathrm{c}}$ & $17.6 \pm 5.3$ & $8.5 \pm 2.5$ & $136(0.08)$ & $17.4 \pm 4.4$ & $22.0 \pm 6.0$ & $192(0.83)$ & $29.0 \pm 5.6$ & $70.3 \pm 18.2$ & $146(0.22)$ & $23.8 \pm 8.3$ & $31.7 \pm 9.4$ & $140(0.16)$ \\
\hline 2. TD probing & $341.0 \pm 21.4$ & $379.9 \pm 12.7$ & $160(0.28)$ & $306.3 \pm 14.7$ & $311.8 \pm 18.7$ & $169(0.40)$ & $297.5 \pm 22.5$ & $298.7 \pm 25.9$ & $180(0.78)$ & $245.5 \pm 19.0$ & $222.6 \pm 27.2$ & $163(0.45)$ \\
\hline 3. NO pathway & $24.5 \pm 3.1$ & $25.0 \pm 2.8$ & $194.5(0.88)$ & $27.4 \pm 3.4$ & $25.7 \pm 1.9$ & $196(0.91)$ & $19.8 \pm 2.4$ & $15.1 \pm 2.4$ & $142(0.18)$ & $22.2 \pm 2.4$ & $21.8 \pm 3.7$ & $168.5(0.55)$ \\
\hline 4. TD pathway & $172.9 \pm 15.6$ & $171.0 \pm 14.2$ & $195(0.89)$ & $222.4 \pm 14.9$ & $201.2 \pm 13.1$ & $163(0.32)$ & $188.1 \pm 15.7$ & $183.6 \pm 18.6$ & $173(0.63)$ & $211.4 \pm 15.7$ & $144.8 \pm 19.0$ & $106(<0.05)$ \\
\hline 5. NO phloem & $0.7 \pm 0.2$ & $1.5 \pm 0.2$ & $106(<0.01)$ & $0.0 \pm 0.0$ & $0.5 \pm 0.2$ & $130(<0.01)$ & $0.7 \pm 0.2$ & $0.3 \pm 0.1$ & $135.5(0.07)$ & $0.1 \pm 0.1$ & $0.3 \pm 0.1$ & $170.5(0.30)$ \\
\hline 6. TD phloem & $97.3 \pm 30.0$ & $140.9 \pm 24.2$ & $130(<0.05)$ & $0.0 \pm 0.0$ & $13.5 \pm 5.9$ & $130(<0.01)$ & $52.1 \pm 19.5$ & $11.2 \pm 6.3$ & $129(<0.05)$ & $3.5 \pm 3.5$ & $16.3 \pm 14.5$ & $172(0.34)$ \\
\hline 7. TD stylet ${ }^{\mathrm{c}}$ & $0.0 \pm 0.0$ & $0.0 \pm 0.0$ & $200(1.00)$ & $1.8 \pm 1.8$ & $0.0 \pm 0.0$ & $190(0.32)$ & $3.6 \pm 3.6$ & $1.3 \pm 1.3$ & $190(1.00)$ & $2.8 \pm 2.8$ & $11.9 \pm 10.6$ & $181(0.58)$ \\
\hline 8. TD xylem ${ }^{\mathrm{c}}$ & $49.1 \pm 10.8$ & $44.0 \pm 8.2$ & $199.5(0.99)$ & $61.5 \pm 11.6$ & $71.7 \pm 9.4$ & $180(0.59)$ & $40.0 \pm 10.2$ & $82.4 \pm 15.5$ & $115(<0.05)$ & $24.7 \pm 5.3$ & $49.0 \pm 10.7$ & $132(0.10)$ \\
\hline \multicolumn{13}{|l|}{ Intracellular ${ }^{\mathrm{d}}$} \\
\hline 9. NO (pd) & $37.4 \pm 3.6$ & $38.1 \pm 3.0$ & $191.5(0.82)$ & $19.7 \pm 3.2$ & $29.7 \pm 2.9$ & $117(<0.05)$ & $14.7 \pm 2.9$ & $20.2 \pm 3.3$ & $144.5(0.20)$ & $15.5 \pm 3.2$ & $17.6 \pm 3.2$ & $180.5(0.79)$ \\
\hline 10. pd Duration & $4.81 \pm 0.12$ & $5.17 \pm 0.12$ & $96(<0.01)$ & $5.76 \pm 0.47$ & $4.85 \pm 0.15$ & $84(<0.01)$ & $5.21 \pm 0.56$ & $5.65 \pm 0.26$ & $180(0.78)$ & $7.95 \pm 0.53$ & $7.08 \pm 0.46$ & $124.5(0.07)$ \\
\hline 11. DS II-1 pd & $1.91 \pm 0.04$ & $2.04 \pm 0.07$ & $157(0.25)$ & $1.87 \pm 0.11$ & $1.66 \pm 0.04$ & $63(<0.01)$ & $1.53 \pm 0.15$ & $1.75 \pm 0.08$ & $163(0.45)$ & $1.77 \pm 0.11$ & $1.44 \pm 0.09$ & $67.5(<0.01)$ \\
\hline 12. DS II- 2 pd & $1.25 \pm 0.03$ & $1.34 \pm 0.03$ & $123(<0.05)$ & $1.17 \pm 0.07$ & $1.14 \pm 0.03$ & $133(0.07)$ & $1.47 \pm 0.15$ & $1.73 \pm 0.07$ & $159(0.38)$ & $1.46 \pm 0.09$ & $1.38 \pm 0.09$ & $151.5(0.28)$ \\
\hline 13. DSII-3 pd & $1.65 \pm 0.08$ & $1.79 \pm 0.06$ & $116(0.05)$ & $2.72 \pm 0.39$ & $2.06 \pm 0.12$ & $108(<0.05)$ & $2.21 \pm 0.33$ & $2.18 \pm 0.20$ & $167(0.52)$ & $4.73 \pm 0.36$ & $4.25 \pm 0.30$ & $142.5(0.18)$ \\
\hline
\end{tabular}

a $\mathrm{TD}=$ total duration, $\mathrm{NO}=$ number of, pathway = pathway phases, phloem $=$ phloem phases, pd = potential drops, and DS = duration of indicated subphase.

${ }^{\mathrm{b}}$ General probing behavior. Occurrence and TD (in minutes) of general probing parameters were calculated for the whole 8-h recording.

${ }^{\mathrm{c}}$ First probe, stylet $=$ stylet derailment, xylem $=$ xylem ingestion.

${ }^{\mathrm{d}}$ Intracellular probing behavior. Occurrence and mean duration (in seconds) of intracellular probing parameters were calculated for the first hour after the first probe; $n=$ number of replicates (aphids), $\mathrm{U}(\mathrm{p})=$ Mann-Whitney $\mathrm{U}$ test value with its probability within brackets. Bold $\mathrm{U}$ (p) indicate significant difference at $P<0.05$. 
tion process, from the host-finding step to the evaluation and acceptance of the host. Infection of potato plants by PVY ${ }^{\mathrm{NTN}}$ did not induce any change in the host location or landing for both the colonizing and noncolonizing aphid species tested. However, in terms of feeding behavior, tested aphids exhibited species-specific responses to infection by PVY-P.

None of the tested aphid species exhibited a preference for either H-Ps or PVY-Ps, not only throughout the experiment but also in their final choice. Attraction of aphids toward plants infected by a persistent or a nonpersistent virus was reported to be partly associated to the yellowing or mottling of leaves $(12,20)$. As reported by Petrovič et al. (38), no macroscopic symptoms can be observed on PVY-infected in vitro plants. Infection by persistent viruses can induce a higher production of headspace volatiles, leading to higher attractivity toward aphids $(11,24,35)$. However, Eigenbrode et al. (11) reported that PVY infection of potato plants did not induce a modification of the total amount of VOCs. Therefore, the equal distribution of aphids on both plants observed in this study could be partly explained by the lack of chemical and visual cues characterizing PVY-P.

Interestingly, $B$. brassicae, although performing interplant movements, was never recorded on plants at the end of the experiment (after $24 \mathrm{~h}$ ). Once landing occurs, brief probes are realized to evaluate host plant suitability through gustatory cues either on host plants $(34,42)$ or nonhost plants $(53)$. Several brief evaluation probes without reaching or ingesting phloem sap were observed in $B$. brassicae, suggesting that Solanum tuberosum was recognized as a nonhost. In contrast, $M$. persicae, once having reached a plant, remained on it and started feeding. The differential ability to realize interplant movements can be linked to the feeding specialization of the different species. Thus, the polyphagous aphid M. persicae realized all the steps of the host plant colonization process, from orientation to settlement, on the first plant that they reached. By contrast, because potato is not a host plant for the other aphid species (2), they only realized the first steps of the plant colonization process, from orientation to gustatory assessment, before rejecting the plant and flying to another one.

As reported by Castle et al. (8) and Hodge and Powell (20), divergent effects have been observed on aphid responses according to the type of virus-vector relationship, ranging from positive to neutral to negative. Despite no sign of preference in the early steps of host plant colonization, the EPG study clearly showed that aphid responses toward PYV-P were species dependent.

The increased phloem phase in $M$. persicae and $S$. avenae may have resulted from a phagostimulant effect of PVY-P. Plants infected by phytoviruses have been reported to show an increase in the amount of carbohydrates and amino acids in their leaves $(7,31)$ and in their general nutritional quality. By contrast, the decreased phloem phase observed in A. fabae may be regarded as a fasting period resulting from an antifeedant effect within phloem vessels benefitting the total duration of xylem sap ingestion. The alteration of phloem sap feeding in A. fabae, as well as the shorter duration of pathways phase in B. brassicae, may be consequent to the induction of chemical (e.g., antifeedant) compounds in vascular and mesophyll tissues of PVY-P. Indeed, potato plants respond to PVY through various defense mechanisms, among which phytohormones $(28,38)$ are well known to interfere with aphid feeding $(5,48)$.

From an epidemiological point of view, EPG parameters such as the time before stylet insertion and those related to brief intracellular punctures were shown to be involved in the transmission of nonpersistent viruses such as PVY $(31,43)$. Interestingly, PVY-P did not induce a delay in probing whatever the aphid species considered. All aphid species realized potential drops; therefore, they are potentially able to transmit nonpersistent viruses. PVY infection increased the mean duration of the virus acquisition phase (II-3 subphase) in M. persicae whereas it decreased it in $S$. avenae. Mean durations of the virus inoculation phase (II-1 subphase) in S. avenae and B. brassicae were reduced on PVY-P. To our knowledge, variations in the duration of these subphases, which are necessary for efficient nonpersistent virus acquisition and inoculation, were never reported to modulate aphid transmission ability.

Evaluation of vector activity, which combines the monitoring of probing activity and movements, allows for an estimation of the behavioral component involved in the spread of phytoviruses (22). Further, vector efficiency is defined as the probability to obtain infected plants with a given virus using a given vector under a given set of conditions (50). Our results suggest that the vector activity of $M$. persicae does not promote PVY spread because it settled on the first plant on which it landed. By contrast, the noncolonizing A. fabae, S. avenae, and B. brassicae exhibited interplant movements associated with plant probing, thereby potentially improving PVY spread. Regarding vector efficiency, several authors determined different rates of PVY transmission for different aphid species $(9,14,18,25,37,55,56)$, among which $M$. persicae is considered to be the most efficient vector of PVY. Considering our evaluation of the vector activity of $M$. persicae and its vector efficiency reported in literature, this species appears to be a sedentary one with a high PVY-transmission rate. Nonetheless, $M$. persicae produces more abundant progeny on PVY-infected plants $(7,49)$ which will, in turn, spread the virus and contribute to the powerful transmission efficiency of this species. Noncolonizing aphids are very mobile species though they present lower PVY-transmission rates. Nevertheless, the high densities of such aphids trapped in potato fields could compensate for their weak transmission efficiency.

This study reports, for the first time, that the same virus could induce a broad range of behavioral modifications depending on the aphid species. Such results could improve our knowledge of PVY epidemics in potato fields: aphids land randomly on plants whatever their status (H-P or PVY-P) and PVY spread mostly relies on the feeding preference exhibited after landing. However, in our experimental conditions, our PVY-P did not exhibit visual symptoms of infection and, although aphids rely mainly on chemical cues for host plant recognition and acceptance, long-range host location may be affected if PVY-P are visually discriminated by aphids. Further experiments are needed to test the hypothesis of visual discrimination by using potato tuber plants or other in vitro plantlets exhibiting visual symptoms when they are infected. According to Sisterson's model (47), the feeding preference for healthy plants increased the rate of pathogen spread as observed in A. fabae. Meanwhile, the feeding preference for infected plants decreased the rate of spread as observed in $M$. persicae. These results suggest that the involvement of colonizing potato aphids in the spread of PVY, which is usually reported in the literature, cannot be explained only by efficient vector activity. With the aim to give valuable information on PVY epidemics in potato crops, vector efficiency of the PVY ${ }^{\mathrm{NTN}}$ isolate has to be assessed in these different aphid species. Such information would be of great interest to understand the propagation strategies of nonpersistently transmitted viruses.

\section{Acknowledgments}

This work was funded by Conseil Régional de Picardie and Comité Nord Plants de Pommes de Terre. We thank F. Lemoine and X. Riquiez for providing healthy in vitro plant lineage and PVY-infected potato tuber and M. Taub for advice on the use of the English language in the article.

\section{Literature Cited}

1. Alvarez, A., Garzo, E., Verbeek, M., Vosman, B., Dicke, M., and Tjallingii, W. F. 2007. Infection of potato plants with Potato leafroll virus changes attraction and feeding behaviour of Myzus persicae. Entomol. Exp. Appl. 125:135-144

2. Blackman, R. L., and Eastop, V. F. 2000. Aphids on the World's Crop: An Identification and Information Guide, 2nd ed. John Wiley \& Sons Ltd., New York.

3. Boiteau, G., Singh, M., Singh, R. P., Tai, G., and Turner, T. 1998. Rate of spread of PVY (N) by alate Myzus persicae (Sulzer) from infected to healthy plants under laboratory conditions. Potato Res. 41:335-344.

4. Brunissen, L., Cherqui, A., Pelletier, Y., Vincent, C., and Giordanengo, P. 2009. Host-plant mediated interactions between two aphid species. Entomol. Exp. Appl. 132:30-38. 
5. Brunissen, L., Vincent, C., Le Roux, V., and Giordanengo, P. 2010. Effects of systemic potato response to wounding and jasmonate on the aphid Macrosiphum euphorbiae (Sternorryncha: Aphididae). J. Appl. Entomol. 134:562-571.

6. Caillaud, M. C. 1999. Behavioural correlates of genetic divergence due to host specialization in the pea aphid, Acyrthosiphon pisum. Entomol. Exp. Appl. 91:227-232.

7. Castle, S. J., and Berger, P. H. 1993. Rates of growth and increase of Myzus persicae on virus-infected potatoes according to type of virus-vector relationship. Entomol. Exp. Appl. 69:51-60.

8. Castle, S. J., Mowry, T. M., and Berger, P. H. 1998. Differential settling by Myzus persicae (Homoptera: Aphididae) on various virus infected host plants. Ann. Entomol. Soc. Am. 91:661-667.

9. de Bokx, J., and Piron, P. 1990. Relative efficiency of a number of aphid species in the transmission of Potato virus $Y^{\mathrm{N}}$ in the Netherlands. Eur. J. Plant Pathol. 96:237-246.

10. Döring, T. F., Kirchner, S. M., Kuhne, S., and Saucke, H. 2004. Response of alate aphids to green targets on coloured backgrounds. Entomol. Exp. Appl. 113:53-61.

11. Eigenbrode, S. D., Ding, H., Shiel, P., and Berger, P. H. 2002. Volatiles from potato plants infected with Potato leafroll virus attract and arrest the virus vector, Myzus persicae (Homoptera: Aphididae). Proc. R. Soc. B Biol. Sci. 269:455-460

12. Fereres, A., Kampmeier, G. E., and Irwin, M. E. 1999. Aphid attraction and preference for soybean and pepper plants infected with Potyviridae. Ann. Entomol. Soc. Am. 92:542-548.

13. Fereres, A., and Moreno, A. 2009. Behavioural aspects influencing plant virus transmission by homopteran insects. Virus Res. 141:158-168.

14. Fereres, A., Perez, P., Gemeno, C., and Ponz, F. 1993. Transmission of Spanish pepper-and potato-PVY isolates by aphid (Homoptera: Aphididae) vector: epidemiological implications. Environ. Entomol. 22:1260-1265.

15. Fereres, A., Shukle, R. H., Araya, J. E., and Foster, J. E. 1990. Probing and feeding behavior of Sitobion avenae (F.) (Homoptera: Aphididae) on three wheat cultivars infected with Barley yellow dwarf virus. J. Appl. Entomol. 109:29-36

16. Giordanengo, P. 2009. EPG-Calc: a PHP program to evaluate EPG parameters. Université de Picardie Jules Verne. http://www.u-picardie.fr/PCP/ UTIL/epg/epg.php

17. Glais, L., Tribodet, M., Gauthier, J. P., Astier-Manifacier, S., Robaglia, C., and Kerlan, C. 1998. RFLP mapping of the whole genome of ten viral isolates representative of different biological groups of Potato virus Y. Arch. Virol. 143:2077-2091.

18. Harrington, R., and Gibson, R. 1989. Transmission of Potato virus $Y$ by aphids trapped in potato crop in southern England. Potato Res. 32:167-174.

19. Heimbach, U., Thieme, T., Weidemann, H. L., and Thieme, R. 1998. Transmission of Potato virus $Y$ by aphid species which do not colonise potatoes. Pages 555-559 in: Aphids in Natural and Managed Ecosystems. J. M. Nieto Nafria and A. F. G. Dixon, eds. Universidad de León, León.

20. Hodge, S., and Powell, G. 2008. Do plant viruses facilitate their aphid vectors by inducing symptoms that alter behavior and performance? Environ. Entomol. 37:1573-1581.

21. Hodge, S., and Powell, G. 2010. Conditional facilitation of an aphid vector, Acyrthosiphon pisum, by the plant pathogen, Pea enation mosaic virus. J. Insect Sci. 10:155

22. Irwin, M. E., and Ruesink, W. G. 1986. Vector intensity: a product of propensity and activity. Pages 13-33 in: Plant Virus Epidemics: Monitoring, Modelling and Predicting Outbreaks. G. D. McLean, R. G. Garrett, and W. G. Ruesink, eds. Academic Press Australia, Sydney, Australia.

23. Jimenez-Martinez, E. S., Bosque-Perez, N. A., Berger, P. H., and Zemetra, R. S. 2004. Life history of the bird cherry-oat aphid, Rhopalosiphum padi (Homoptera: Aphididae), on transgenic and untransformed wheat challenged with Barley yellow dwarf virus. J. Econ. Entomol. 97:203-212.

24. Jimenez-Martinez, E. S., Bosque-Perez, N. A., Berger, P. H., Zemetra, R. S., Ding, H., and Eigenbrode, S. D. 2004. Volatile cues influence the response of Rhopalosiphum padi (Homoptera: Aphididae) to Barley yellow dwarf virus-infected transgenic and untransformed wheat. Environ. Entomol. 33:1207-1216

25. Kanavaki, O. M., Margaritopoulos, J. T., and Katis, N. I. 2006. Transmission of Potato virus $Y$ in tobacco plants by Myzus persicae nicotianae and M. persicae s. str. Plant Dis. 90:777-782.

26. Kennedy, J. S., Day, M. F., and Eastop, V. F. 1962. A Conspectus of Aphids as Vectors of Plant Viruses. Commonwealth Institute of Entomology, London

27. Koch, E., and Slusarenko, A. 1990. Arabidopsis is susceptible to infection by a downy mildew fungus. Plant Cell 2:437-445.

28. Kovač, M., Müller, A., Milovanovič Jahr, M., Milavec, M., Düchting, P., and Ravnikar, M. 2009. Multiple hormone analysis indicates involvement of jasmonate signalling in the early defence of potato to Potato virus $Y^{\mathrm{NTN}}$. Biol. Plant 53:195-199.
29. MacKay, P. A., and Downer, R. 1979. Water content, weight change, an activity of apterous and alate virginoparous Acyrthosiphon pisum (Harris)(Homoptera: Aphididae). Can. J. Zool. 57:363-367.

30. Markkula, M., and Laurema, S. 1964. Changes in the concentration of free amino acids in plants induced by virus diseases and the reproduction of aphids. Ann. Agric. Fenn. 3:265-271

31. Martin, B., Collar, J. L., Tjallingii, W. F., and Fereres, A. 1997. Intracellular ingestion and salivation by aphids may cause the acquisition and inoculation of non-persistently transmitted plant viruses. J. Gen. Virol. 78:27012705.

32. Medina-Ortega, K. J., Bosque-Pérez, N. A., Ngumbi, E., Jiménez-Martínez, E. S., and Eigenbrode, S. D. 2009. Rhopalosiphum padi (Hemiptera: Aphididae) responses to volatile cues from Barley yellow dwarf virusinfected wheat. Environ. Entomol. 38:836-845.

33. Murashige, T., and Skoog, F. 1962. A revised medium for rapid growth and bio assays with tobacco tissue cultures. Physiol. Plant. 15:473-497.

34. Nault, L. R., and Styer, W. E. 1972. Effects of sinigrin on host selection by aphids. Entomol. Exp. Appl. 15:423-437.

35. Ngumbi, E., Eigenbrode, S. D., Bosque-Perez, N. A., Ding, H., and Rodriguez, A. 2007. Myzus persicae is arrested more by blends than by individual compounds elevated in headspace of PLRV-infected potato. J. Chem. Ecol 33:1733-1747.

36. Niemeyer, H. M. 1990. The role of secondary plant compounds in aphidhost interactions. Pages 187-205 in: Aphid-Plant Genotype Interactions. R. K. and Campbell R. D. Eikenbary, eds. Elsevier, Amsterdam.

37. Perez, P., Collar, J. L., Avilla, C., and Duque, M. 1995. Estimation of vecto propensity of Potato virus $Y$ in open-field pepper crops of central Spain. J. Econ. Entomol. 88:986-991.

38. Petrovič, N., Miersch, O., Ravnikar, M., and Kovač, M. 1997. Potato virus $Y^{\text {NTN }}$ alters the distribution and concentration of endogenous jasmonic acid in potato plants grown in vitro. Physiol. Mol. Plant Pathol. 50:237-244.

39. Pickett, J. A., Wadhams, L. J., Woodcock, C. M., and Hardie, J. 1992. The chemical ecology of aphids. Annu. Rev. Entomol. 37:67-90.

40. Powell, G. 1991. Cell membrane punctures during epidermal penetrations by aphids: consequences for the transmission of two potyviruses. Ann. Appl. Biol. 119:313-321.

41. Powell, G. 2005. Intracellular salivation is the aphid activity associated with inoculation of non-persistently transmitted viruses. J. Gen. Virol. 86:469472.

42. Powell, G., and Hardie, J. 2000. Host-selection behaviour by genetically identical aphids with different plant preferences. Physiol. Entomol. 25:5462.

43. Powell, G., Pirone, T., and Hardie, J. 1995. Aphid stylet activities during potyvirus acquisition from plants and an in vitro system that correlate with subsequent transmission. Eur. J. Plant. Pathol. 101:411-420.

44. Powell, G., Tosh, C. R., and Hardie, J. 2006. Host plant selection by aphids: behavioral, evolutionary, and applied perspectives. Annu. Rev. Entomol. 51:309-330.

45. Power, A. G. 1996. Competition between viruses in a complex plant-pathogen system. Ecology 77:1004-1010.

46. Sigvald, R. 1984. The relative efficiency of some aphid species as vectors of Potato virus $Y^{\mathrm{O}}\left(\mathrm{PVY}^{\mathrm{O}}\right)$. Potato Res. 27:285-290.

47. Sisterson, M. S. 2008. Effects of insect-vector preference for healthy or infected plants on pathogen spread: insights from a model. J. Econ. Entomol. 101:1-8

48. Slesak, E., Slesak, M., and Gabrys, B. 2001. Effect of methyl jasmonate on hydroxamic acid content, protease activity, and bird-cherry oat aphid Rhopalosiphum padi (L.) probing behavior. J. Chem. Ecol. 27:2529-2543.

49. Srinivasan, R. and Alvarez, J. M. 2007. Effect of mixed viral infection (Potato virus $Y$-Potato leafroll virus) on biology and preference of vectors Myzus persicae and Macrosiphum euphorbiae (Hemiptera: Aphididae). J. Econ. Entomol. 100:646-655.

50. Sylvester, E. S. 1954. Aphid transmission of nonpersistent plant viruses with special reference to the Brassica nigra virus. Hilgardia 23:53-98.

51. Tjallingii, W. F. 1988. Electrical recording of stylet penetration activities Pages 95-108 in: Aphids: Their Biology, Natural Enemies and Control. A. K. Minks and P. Harrewijn, eds. Elsevier, Amsterdam.

52. Tjallingii, W. F., and Hogen-Esch, T. 1993. Fine structure of aphid stylet routes in plant tissues in correlation with EPG signals. Physiol. Entomol. 18:317-328.

53. Tosh, C. R., Powell, G., and Hardie, J. 2003. Decision making by generalist and specialist aphids with the same genotype. J. Insect Physiol. 49:659-669.

54. Van Harten, A. 1983. The relation between aphid flights and the spread of Potato virus $Y^{\mathrm{N}}\left(\mathrm{PVY}^{\mathrm{N}}\right)$ in the Netherlands. Potato Res. 26:1-15.

55. Van Hoof, H. A. 1980. Aphid vectors of Potato virus $Y^{\mathrm{N}}$. Eur. J. Plant Pathol. 86:159-162.

56. Verbeek, M., Piron, P. G. M., Dullemans, A. M., Cuperus, C., and van der Vlugt, R. R. A. 2010. Determination of aphid transmission efficiencies for N, NTN and Wilga strains of Potato virus Y. Ann. Appl. Biol. 156:39-49. 